\title{
Realizing global justice: Theory and practice
}

\section{Melina Duarte \& Tor Ivar Hanstad}

The image on the front cover (also on page 10) of this special issue of Etikk $i$ praksis composed the official poster of the conference Realizing Global Justice: Theory and Practice. The conference took place at UiT The Arctic University of Norway, Tromsø, in June 2013 and it was hosted by the Pluralism, Democracy, and Justice Research Group (www.uit.no/pdj). Contributors were invited to reflect upon the image from different philosophical perspectives. The image is powerful and intriguing. The portrayed scene is familiar, but still causes discomfort. We have the impression that our eyes could have captured the scene in almost any country in the world, although it was taken in Porto Alegre, Brazil, by the Brazilian photographer Rodolfo Gil.

A man is sitting on a stone bench. The bench is clearly designed for leisure. It is a place where people are supposed to stop for a short pause after a walk in pleasant park scenery; a place where people are used to relaxing before rushing off to the next appointment, where they can read the newspaper, have lunch, or merely take a break and contemplate nature. What all these uses of the park bench have in common is an assumption that the person sitting there has some other place to be. The image, however, exposes a homeless man, a vagrant, sitting on a park bench "somewhere" in the world. The homeless man on the bench symbolizes a stark contrast to the original functionality of the park bench. He is not using the bench for a much-needed break from any work at all, and the likelihood of him using the bench for recreation is also very low. On the contrary, it is likely that the man in the photo uses the bench as one of many "homes" that he drifts between. The luxury of leisure time on a bench in the park is, in this sense, something from which he is excluded. From that perspective, the image uses this representation of exclusion to effectively illustrate core problems that are inscribed into the urgent demands of global justice.

The issues at stake in this representation are complex ones indeed. We want to know what brought that man to this position. Was it through some fault of his own? We might agree that it can hardly be his true wish to live in constant and painful deprivation. Perhaps, resigned, he is no longer able to realize his wishes and needs beyond survival. Inured with exclusion, he might expect very little from life. He must have learned that life is hard and unfair after all, or maybe he thinks he does not deserve anything better. But then, if we can agree that the exclusion is not, or at least not entirely, his fault, would those able to use the bench for merely recreational purposes be guilty for his state to some extent? Do they carry any responsibility towards the man? Which kind of responsibilities would have to be considered? Who should be expected to respond to this issue: citizens, states, international organizations?

In this special issue of Etikk i Praksis on global justice, we have turned our attention to the conflicting perspectives of justice in theory and in practice. We were guided by the need to approach these concrete questions and make the ideal theories of justice relevant for those who are living on a bench somewhere in the world and clamouring for justice right now. Here we meet one of the classic and most enduring conflicts within political and moral philosophy, which dates back to Plato and Aristotle. The question is what contribution political 
philosophers, or philosophers in general, can make to current political practices. On the one hand, within a more theoretical framework, the role of political philosophy is to formulate a theory of justice from an abstract, atemporal and conceptually coherent point of view. This perspective seeks to unveil what is necessary in human nature without being limited or disturbed by contingencies. Actors are oriented towards disentangling eternal truths about the idea of justice that would, in principle, set the pillars for contextual approaches. On the other hand, from a more practical framework, formulating definitions of justice and justifying them on purely theoretical grounds are not enough to bring justice for people who are in urgent need. The main concern here is to communicate ways to promote as much justice as possible today, while also considering the constraints that our societies impose. Actors using this framework diagnose our institutions, looking at how to best organize them in order to actually implement more just practices, or how to distribute laws, taxes, and rights in this context.

Confronting these apparently divergent perspectives, we have to ask whether it is possible to create a society that on a 1:1 scale mimics perfectly the theoretical image of justice; or whether there will always be a gap between theoretical perfection and a reality that repeats imperfection and resistance. On the one hand, the actual reality is rarely absolutely relevant in the most theoretical frameworks. In the most practical frameworks, on the other hand, the stance is that no reality can be made or shaped to fit theoretical models entirely. While theoretical models can be used as signposts that point to possible political directions, the realities on the ground need to inform the guiding principles that must be interpreted, adjusted and implemented in light of the overall context.

Despite the difficulties, this impasse should not prevent political philosophers from engaging the challenges that come with a problematic encounter between theory and practice. After all, whatever is unjust in this world has been created through human actions, guided by ethical, moral and political principles that can be reversed. Even if the sheer magnitude of a complex issue may make it look like an insurmountable obstacle, human constructs can be reconstructed. We do know that reforms that have led to more justice have not come easily. Debates, struggles and even wars have preceded them. In this sense, the world is never just, but must continually be made more just. With the emergence of globalized societies and the instability of national borders, today's challenge for political philosophers seems to be to expand the domestic basic understanding of justice so that it also covers global justice. In any case, whether they bring updated ideas of justice in a theoretical sense, or bring theories on institutional or other practical designs, there is still a lot that political philosophy can bring to the table. This special issue attempts to combine both perspectives and move beyond the old accepted dichotomy between theory and practice.

In a "Non-ideal Global Basic Structure," Sabrina Martin explains and deconstructs the dichotomy raised by statists and cosmopolitan theories of justice. She acknowledges that the debate on global justice has been largely polarized. One side argues that there is a lack of a global basic structure capable of supporting the demands of justice at this level, whereas the other side maintains that the existing global basic structure is sufficient to start expanding the current domestic obligations of justice globally. In both cases, the divergence is grounded in the assertion that the basic structure is a precondition for the demands of justice to arise. Thus, the justification for determining the scope of justice domestically or globally is seen as being dependent on establishing either a domestic or global basic structure. As the author acknowledges, these two positions are also respectively often identified with non-ideal, and ideal, theories of justice. While the statist or non-ideal positions aim at guiding actions applicable in an actual and determined society, the cosmopolitan or ideal approaches posit 
abstract empirical and contingent facts that idealize some aspects of society. In light of Ronzoni's (2009) practice-dependent approach, Martin argues that, given a Rawlsian conception of justice, the basic structure does not always arise before the demands of justice do. In these cases, the basic structure becomes a subject to, rather than a condition of, the demands of justice. The scope of these demands determines whether the basic structure will be domestic or global. This implies that we are not limited to one of these positions as our starting point. In contrast to Ronzoni, Martin claims that the conditions and circumstances that give rise to the need for a basic structure must be further specified. Otherwise, justice will never appear global in scope and the establishment of a global basic structure will be seriously compromised. These conditions and circumstances are rather given by the experiences of injustice that can be empirically verified either domestically or globally. Martin formulates her non-ideal account of a global basic structure on this basis, showing that the debate on global justice must go beyond the polarization between statist and cosmopolitan positions and their formerly correlated, non-ideal and ideal theories.

In "Compatriot Partiality and Cosmopolitan Justice: Can We Justify Compatriot Partiality Within the Cosmopolitan Framework?", Rachelle Bascara presents some circumstances in which an overemphasis on national identity might not only be admitted but also desired, even within cosmopolitan approaches. She investigates when it justifiable to favour our compatriots. Particularists such as Thomas Hurka (1997) would say that our duties are, if not restricted to, at least preferential to our fellow citizens. Conversely, cosmopolitans such as Thomas Pogge (2008) and Richard Arneson (2004), appealing to a strong commitment to a moral universalism, would say that such a choice is not justifiable within a cosmopolitan framework. In the latter perspective, individuals share equal moral standing, and to favour someone based on their nationality cannot not be legitimate. Moreover, other critics of compatriot partiality, such as Paul Gomberg (1990) and Simon Keller (2005), have successfully pointed out the striking similarities between compatriot and racial partiality. Bascara, however, challenges the standard cosmopolitan approaches that reject compatriot partiality by default. The author masterfully defends an intriguing thesis, stating that although we have no universalizable moral reasons to prioritize our fellow citizens over others, considering the current power disparity between rich and poor countries, we do have strong instrumental reasons to accept certain types of compatriot partiality such as those coming from highly oppressed countries. In these particular cases, compatriot partiality would enable people to enhance their commonality within their borders and their claim for emancipation internationally. Therefore, Bascara argues that it is possible to justify compatriot partiality within the cosmopolitan framework, on the same grounds that we justify liberation movements and affirmative action. The defence is not based on a universal moral code, she says, but it is dependent on the unjust global context in which we are living today. Thus, because cosmopolitans are committed to the realization of global justice, they should see compatriot partiality as a temporary useful tool to promote a country's bottom-up emancipation and liberation in the global arena.

In "Should She Be Granted Asylum? Examining the Justifiability of the Persecution Criterion and Nexus-clause in Asylum Law," Noa Wirth Nogradi turns our attention to the negative side of compatriot partiality when bringing up the limitations of refugee policies. Currently, there are more than 65 million forcibly displaced people worldwide, of which more than 20 million are refugees, the greatest number ever recorded (UNHCR 2015). Intolerance and war are among the main drivers of this massive displacement of persons from their homeland. Source and destination countries have been significantly affected by this 
phenomenon, making the right to asylum and the refugee policies a global issue that requires constant examination and improvement. According to the 1951 Refugee Convention and its 1967 Protocol, all persons forced to leave their country in order to avoid persecution based on "race, religion, nationality, or membership in a particular social or political group" (Article IA(2)) are classified as refugees. However, Nogradi reveals that other vulnerable groups such as women are unjustifiably not included in this list. Despite the actual recognition of numerous and long-term gender-based injustices committed against women, several categories of persecuted women cannot claim asylum based on these grounds. Rather, they must show that their persecution fits one of the criteria listed in Article IA(2). Nogradi uses Kuosmanen's (2014) definition of persecution to show that gender-based injustices are not a usual harm as they have been considered until now, but a form of persecution, which makes the 1951 Convention incomplete. Persecution comprises "asymmetrical and systemic threat, severe harm, and unjust discriminatory targeting," and these criteria match the circumstances still faced by many women today. By denouncing this gap between the 1951 Refugee Convention and the current definition of persecution, she points out the necessity of revising not only the refugee policies, but also the humanitarian and political justifications that are grounded in the right to asylum. Nogradi's paper exposes the fact that the whole theoretical and practical debate on refugee rights is now back at square one. She argues that new theories and more inclusive policies are urgently needed.

In "Lives Rendered Invisible: Bearing Witness to Human Suffering," Mladjo Ivanovic investigates how the worldwide overexposure to images of atrocities can affect the public's capacity to react to global injustices. In principle, this mechanism can have two effects: first, that we become desensitized to images of suffering, and secondly, that we come to see the images of suffering as pure representations of suffering "as it is", i.e. without any ideological bias. Ivanovic contests the latter presupposition, and in so doing, he directs the attention to what may be a blind spot in our reception of representations of suffering. An example that illustrates the latter mechanism and how it operates is the famous and paranoid justification by the former American Secretary of Defense, Donald Rumsfeldt, for the Iraq War. According to Rumsfeldt, Saddam Hussein's regime had to be toppled because of the uncertainty about what Hussein's actual intentions were. As Rumsfeldt proclaimed, there were "known knowns," "known unknowns" and "unknown unknowns," and it was the last part that made critics shake their heads in disbelief. If "unknown unknowns" are justification enough for invading a country, then it had to mean that the US government reserved carte blanche for itself to invade any country at any time, since after all, there will always be unknown unknowns. However, Slavoi Zizek has pointed out that the existence of "unknown knowns" (Zizek 2014) is the missing and fourth alternative in Rumsfeldt's "analysis" that would render his paranoid version a truly critical one. What slipped under Rumsfeldt's radar was the insight that by turning his gaze to his own underlying presuppositions and biases, he could actually expand his knowledge about his own thoughts and actions. If Rumsfeldt had tried to dig into this, he would have explored the Freudian unconscious, or 'the knowledge that doesn't know itself (Lacan cited in Zizek 2014). Luckily, those we might label critical theorists address and articulate this shift in perspective, and we should not underestimate the value of true critical theory. In his paper, Ivanovic gives us an example of how critical theory at its best can make us think and reflect upon "unknown knowns" in our own culture. More specifically, he discusses how injustices are represented in public through the medium of images, and the effects of these representations. The discussion is conducted on two levels, which are interwoven. First, Ivanovic discusses the direct relationship between images (e.g. of suffering, 
injustice) and the potential de-sensitizing effect this may have. This debate follows the wellknown trails of other similar debates recently, for example whether violent video games lead to more violence, or to a more de-sensitized public when it comes to violence in general. On the second and more critical level, Ivanovic raises the question and discusses why certain types of images (and their contexts) are regarded as "images of suffering and injustice". Through this portal, he applies the method of turning our gaze ruthlessly towards the hegemonic structure of justice/injustice that represents the "unknown knowns" in our own culture. In so doing, he reveals our own presuppositions, biases and, perhaps most important of all, our own "blind spots" when it comes to justice, and how these shape justice frameworks.

In "Climate Change Denial, Freedom of Speech and Global Justice," Trygve Lavik provokes readers to engage more responsibly in the global debate on climate change. Nowadays, the question is no longer about whether the climate is changing or not, but what the causes of the change are. In this debate, the actors form two parties: (1) one claims that climate change is part of natural climate cycles that have always influenced the climate on Earth and are not caused partly or primarily by human activity; (2) the other claims that human activity is the main driver of the changes. In this context, the term "climate denier" refers to those who belong to the "natural causes" camp rather than to those who do not believe in the existence of climate change at all. At this point, the debate between the two groups becomes an epistemological one. What is true and what is false, and, more importantly, what weight should science have in this matter? Another component of the debate concerned with climate change deals with philosophical issues on global justice, such as how we should respond ethically and politically to the challenges that climate change brings about. What kinds of changes to our lifestyle, consumer patterns, and agricultural practices, among others, are necessary? If changes are required, how should they be implemented and by whom? Is a socalled "green economy" compatible with a capitalist economy, or does the term also imply alternative economy(ies)? The questions discussed in this field resemble classic issues that characterize any ethical and political debate. However, two important aspects differentiate the debate on climate change from other debates. First, the epistemological side has a direct impact on the ethical and political side. If climate change is not caused by human activity, the counter-measures against the negative effects of climate change will be looked at differently than if they are human made ("Why change our lifestyle if it has no impact on the climate?"). Secondly, the potential scale of the problem is also different from traditional "small scale" international and domestic politics. If climate change, in the end, makes the planet more or less inhabitable for human beings, and we are the cause, then clearly this gives the climate issue an extra, almost existential dimension way beyond what we normally find in ethical and political debates. And, once again, the conclusions here are dependent upon the epistemological conclusion. In his paper, Lavik goes straight to the core of the epistemological side of the climate change debate. He discusses, to some perhaps provocatively, the question of whether arguments that are utterly false, seen from a scientific point of view, should be banned or not. The crux of Lavik's paper is not whether climate change is happening or not, but its causes. On this issue he finds the scientific evidence in favour of man-made causes overwhelming. The hard question that Lavik boldly grabs by the horns is: how should we deal with those who, defined as "climate deniers", campaign against scientific evidence in the name of self-interests? Here we should be aware of a very fine and exact distinction that Lavik makes between arguments against the scientific evidence to date on scientific grounds (i.e. peer reviewed, open to scrutiny, transparent data sets), and arguments presented in outright marketing campaigns that clearly ignore and overlook scientific evidence. Lavik draws an 
analogy with the campaigning undertaken by the tobacco industry in order to suppress and spread doubt about the scientific evidence on the negative health effects of smoking. Add to this the potential consequences of a worst-case scenario when it comes to climate change, and the questions raised by Lavik may not seem so radical and extreme anymore. Lavik's paper also raises the more general question of whether problems that affect all of mankind one way or another (not to mention future generations) are best solved democratically, or if the time has come to think about other global organizing principles, such as an "expertocracy" or "epistemocracy". In this sense, Lavik does what philosophers are supposed to do, namely raise the tough questions that no one else dares to ask.

In "Stand against Poverty," Prof. Thomas Pogge from Yale University is interviewed on the topic of poverty, by far the most urgent issue in the global justice debate. Despite some disputable advances, half of the world's entire population lives on less than $\$ 2.50$ a day. Furthermore, one billion children live in poverty and 1.4 billion children lack access to safe drinking water and adequate sanitation. Considering these very pressing issues, he believes that it is time for philosophy to guide us to critically needed practical solutions. Prof. Pogge has dedicated his life and career to developing proposals that have strong relevance for political philosophers, from both theoretical and practical traditions, as well as for policy makers. He proposed implementing an alternative form of rewarding the pharmaceutical industry for its innovations, linked to the health impact that they cause. He also proposed instituting a Global Resources Dividend, a global form of taxation that would charge states for their use of the Earth's natural resources. Currently, Pogge is developing new ways to measure poverty and gender disparities, as well as to combat the corruption involved in tax havens and secrecy jurisdictions. In this interview, Pogge focuses on the situation in Brazil, a country that, he says, can exert its increasing influence on the design of global institutions. He anticipates Brazil's challenges in combating poverty and gender disparities. He discusses the positive and negative aspects of the Bolsa Familia (Family grant) programme and suggests that the government should extend its benefits to a larger proportion of the population in order to gain more support from the public. Pogge considers the Bolsa Família a well-designed programme and believes that its implementation is essential to mitigate the absurd inequalities that so strongly polarize society and jeopardize democracy in Brazil. To distribute resources to the poor is not a question of charity, as it was considered in the old days, he explains. He finds no justification for affluent Brazilians controlling all the country's resources while the poor are deprived of their fair share. Pogge is also concerned that, owing to increasing capital mobility, globalization will tend to benefit Brazil's rich, who also find it much easier to evade taxes. Therefore, in addition to extending social programs, Pogge recommends that the Brazilian government ensure that the country's wealth is properly taxed and distributed.

In "A Critical Theory of Democratic Agency," Associate Prof. Eva Erman from Uppsala University is interviewed on the emergence of new global forms of democratic agency. Does the worldwide spread of popular movements represent the rise of a new form of democratic agency? Is it still possible to argue for a non-capitalistic world? In this interview, we follow the conversation between two scholars with different views on democratic agency. The debate is rich, and the reader benefits from simultaneously encountering the arguments and counterarguments in an ongoing debate. Interviewer Øyvind Stokke sees a place in our current societies for a new critical theory to emerge in connection with the spread of popular movements being organized around the world. In this sense, the popular movements that are striving for human emancipation would then draw attention to the sectors requiring the social 
critics. To Stokke, the German Critical Theory can nowadays be expanded, providing both descriptive and normative grounding for liberation claims. Consequently, he believes that sociological and philosophical social critics are not mutually exclusive. Rather, a social critic offers value only when combining both approaches in interdisciplinary accounts. Within the Critical Theory framework, he questions whether capitalist societies can be improved or even reversed by engaging new forms of democratic agency that, in the Habermasian sense, involve deliberation and cooperation. Erman has a different view concerning these topics. She asserts that it is too early to know which role these social movements play from a democratic standpoint. Our task would then be to ask more fundamental questions related to the possible implications of generalizing such movements and to the role that these movements ought to play from a democratic perspective. Erman believes that these movements still fail to engage more formal and legally binding forms of decision-making. She argues that there is an essential difference between "democratic agency" and "agents of democracy" that needs to be taken into account when debating the issue. Other distinctions are equally important to her, such as the distinction between normative and descriptive theories, as well as between practical normativity and normativity of meaning. Although she maintains these distinctions, she is not arguing that normative principles are totally independent from facts. She finds the engagement with actual facts to be fundamental. But that does not mean that the arguments from "is" to "ought" should be mixed up. Finally, instead of thinking how democracy can improve or even reverse capitalism, Erman proposes to turn our attention to the structural problems of capitalism that jeopardize democracy.

In "On Reconciling Care and Justice," Prof. Tove Pettersen from the University of Oslo is interviewed on the challenges of reconciling care and global justice. Interviewer Tomasz Jarymowicz wonders whether the ethics of care is still a feminist affair or if it has now become a global one. He seeks to investigate the reasons behind the current increasing interest in a theory that can be traced back to the 1980s. Originally, the ethics of care emerged from the feminist reaction to the intriguing results of empirical studies run by the prominent psychologist, Lawrence Kohlberg. In his studies, Kohlberg suggested that women did not have the same capacity for moral abstraction as men. In response to that, Carol Gilligan published the seminal work entitled In a Different Voice (1982), claiming that women and men in fact had different ways of manifesting their moral development and that they therefore could not be measured using the same scale. This claim gave rise to hundreds of other studies attempting to reclaim morality as a women's attribute. Many of these studies contributed critically to distancing women's and men's moral development - to the point of implying that they come from different planets, men from Mars and women from Venus. From this perspective, care was associated with women's affairs while justice was associated with men's affairs. In her work, however, Tove Pettersen moves away from this division. She believes that redefining the concept of care can reconcile it with justice and better provide a much needed and more effective account of global justice. Care is usually understood as a one-way activity, but she argues that when understood as a reciprocal activity, care and justice become dependent on each other "like two sides of the same coin".

We have two articles in the Open Section of this issue. In the paper "Er kliniske etikkkomiteer i den kommunale helse- og omsorgstjenesten bærekraftige?" (“Are clinical ethics committees in the municipal health and care services sustainable?") by Lillian Lillemoen, Irene Syse, Reidar Pedersen, and Reidun Førde, the authors discuss to what extent clinical ethics committees (CECs) contribute to maintaining local quality and competence development. Based on their study, the authors argue that the committees are poorly anchored in the 
administrative leadership of the municipalities. The authors suggest that the mandate of these committees should be national rather than municipal, and that their resource situation needs to be strengthened in order for the CECs to contribute to maintaining and developing local quality and competence.

In "Ethical Implications of a Co-benefits Rationale within Climate Change Mitigation Strategy," Rita Vasconcellos Oliveira and May Thorseth point out potential pitfalls in the use of collateral benefits to promote climate change mitigation efforts. The so-called co-benefits rationale is increasingly used to sustain and promote positive attitudes towards climate change mitigation, but by analysing the literature and policy documents of two concrete examples, the authors argue that such a practice can compromise the prime objective unless it is given adequate moral framing.

\section{Acknowledgments}

We thank the Brazilian photographer, Rodolfo Gil, for authorizing the reproduction of his image entitled "The Park Bench" on all occasions related to the conference and conference proceedings; and the Pluralism, Democracy and Justice (PDJ) Research Group of the Department of Philosophy at the UiT The Arctic University of Norway for funding the Realizing Global Justice: Theory and Practice conference and paper collection. Those activities were part of the "Justice in Conflict" project (2012-2015).

We are also grateful to the resident editors of EiP and to the anonymous referees for this special issue. Their careful reading of the submissions and their excellent recommendations have enhanced the quality of the papers in this collection.

\section{References}

Arneson, R. (2004). Do patriotic ties limit global justice? The Journal of Ethics, 9(1), 127-50. http://dx.doi.org/10.1007/s10892-004-3323-x

Gilligan, C. (1982). In a Different Voice. Cambridge, MA: Harvard University Press.

Gomberg, P. (1990). Patriotism is like racism. Ethics, 101(1), 144-50. http://dx.doi.org/10.1086/293264

Hurka, T. (1997). The justification of national partiality. In The Morality of Nationalism, eds. R. McKim and J. McMahan, 139-157. New York: Oxford University Press.

Keller, S. (2005). Patriotism as bad faith. Ethics, 115(3), 563-92. http://dx.doi.org/10.1086/428458

Kuosmanen, J. (2014). What's So Special About Persecution? Ethical Theory and Moral Practice, 17(1), 129-140. http://dx.doi.org/10.1007/s10677-013-9425-4.

Pogge, T. (2008). World Poverty and Human Rights. 2nd ed. Cambridge: Polity.

Ronzoni, M. (2009). The global order: A case of background injustice? A practice-dependent account. Philosophy \& public affairs, 37(3), 229-256. http://dx.doi.org/10.1111/j.10884963.2009.01159.x. 
UN General Assembly, Convention Relating to the Status of Refugees, 28 July 1951, United Nations, Treaty Series, vol. 189, p. 137, available at:

http://www.refworld.org/docid/3be01b964.html [accessed 29 September 2016]

UNHCR. (2015). UNHCR - Global Trends Report 2012. Retrieved from:

https://s3.amazonaws.com/unhcrsharedmedia/2016/2016-06-20-global-trends/2016-06-

14-Global-Trends-2015.pdf

Zizek, S. (2014). Event - Philosophy in Transit. London: Penguin.

\section{Guest editors for Etikk i praksis 2/2016}

Melina Duarte $(\mathrm{PhD}$, Researcher at the Department of Philosophy, UiT The Arctic University of Norway).

E-mail: melina.duarte@uit.no

Tor Ivar Hanstad (Head of the PDJ, Vice-head of the Department of Philosophy, and Lecturer at the UiT The Arctic University of Norway).

E-mail: tor.ivar.hanstad@uit.no 


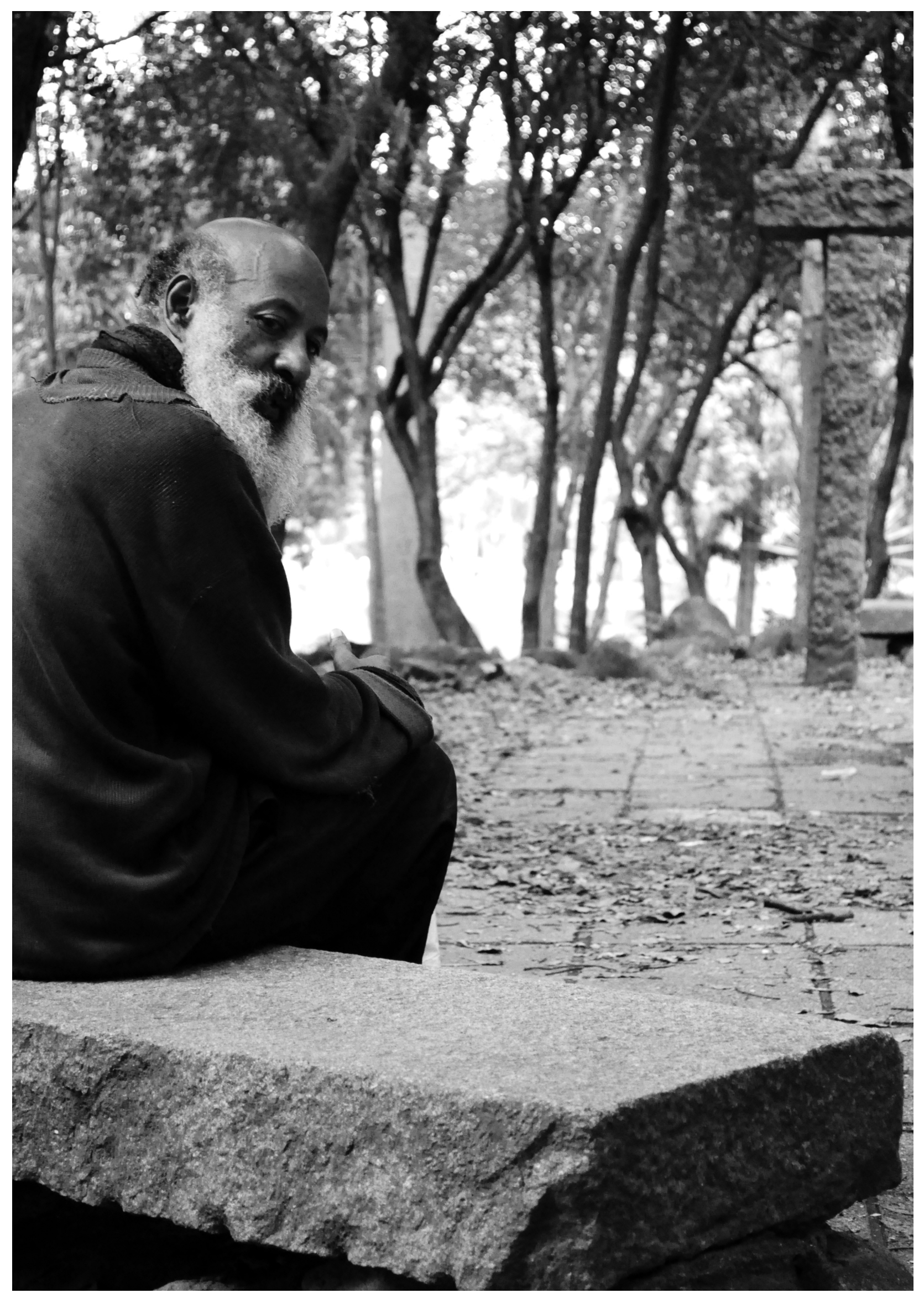

Photograph by Rodolfo Gil, The Park Bench 